\title{
Study on the Performance of Permeable Concrete in Sponge City Construction
}

\author{
Ping Gan, Zhizhang Wan \\ Nanchang Institute of Science \& Technology, Nanchang, Jiangxi, 330108
}

Keywords: Sponge City, Permeable Concrete, Performance Study.

\begin{abstract}
Sponge city refers to the environment in the natural disasters, the city has a good "elastic", the rainy season on the water from the absorption, savings, infiltration and purification, when needed "release" re-use. Through the sunken green space, paving and green roof and other measures, can effectively reduce the "heat island effect", the city and runoff pollution, water conservation, improve and protect the ecological environment, which permeable pavement for the development of permeable concrete ushered opportunity. It is green eco-type foam with green, smoke, porosity, light, breathable and good water permeability and so on. In addition, it can be applied to rivers, rivers, lakes, seaside and other waters and coastal areas, play sand, solid embankment, through the role of water, this paper is a series of studies on the above issues.
\end{abstract}

\section{Introduction}

Sponge city is in the environment changes, natural disasters, the city can like a sponge as a good "elastic", the rainy season when the water from the absorption, savings, infiltration and purification, demand "release" use. The maximum use of the original topography is to play the role of rain accumulation, natural infiltration, vegetation and wetlands on the natural purification of water quality. With the speed of China's capital construction is accelerating, the construction area is increasing, the urbanization process is getting faster and faster, the road is more and more, the impervious area is increasing, and the coverage rate of the domestic urban roads has reached $7 \%$ $15 \%$, About $20 \%$ of big cities. China's urban development in the neglect of the ecological balance, so that it lost the "elastic", often resulting in urban rain water, heavy rain, water black, heat island and other environmental problems serious, send some of the concrete structure is caused by improper of. As the hardening of concrete pavement impermeable, so that rain and groundwater circulation block, destroyed the natural water system, is not conducive to groundwater supplement, so that a serious decline in groundwater level. (The main pollutants are suspended solids, oxides, $\mathrm{N}$ and $\mathrm{P}$, etc.); also because the ordinary concrete airtight is difficult to heat convection with the air, but also because of the large amount of precipitation and sewage discharged into the river outside, The ability to control the surface humidity and temperature, the heat capacity is small, heat absorption force, so that the average surface temperature rise, it formed a "heat island effect", high temperature weather than the ground than $18{ }^{\circ} \mathrm{C}$.

\section{Permeable Concrete Concept}

Permeable concrete with cement is as a cement material, the use of single or discontinuous graded coarse aggregate, containing a small amount or without the preparation of fine aggregates of the porous structure of the coagulation of the main, mainly by the package in the the aggregate of the thick aggregate surface is hardened and the aggregate particles are adhered to. Often used in the strength requirements are not high, with good penetration of the occasion, such as parking, paving the park, the new stadium and so on. Permeable concrete pavement generally contains $15-25 \%$ through the pores, water permeability can generally reach 200L / (m2.min). Effective collection of rainwater or infiltration of groundwater, is conducive to maintaining the balance of groundwater resources to prevent water level drop and ground subsidence, to create a comfortable living 
environment; due to good ventilation is conducive to surface microbial habitat survival, to maintain the natural biological chain; also has noise, Absorb heat, ease the "heat island effect" and so on.

Ordinary permeable concrete raw materials: water, cement and aggregate, need to play when the addition of additives and other additives. (1) cementing material. Including: cement, mineral traits and organic cementing materials. According to the requirements of "ordinary syrup cement" (GB175-2007), permeable coagulation: I should take the mixed material consultation less, higher strength of the salt cement, the label is best on the $42.5 \mathrm{~W}$. The amount of cement mortar in the aggregate surface just happens to form a layer of symmetrical cement mortar film for the best, too much will increase the cost and reduce the permeability. Organic gluing materials include cyan and polymer resins. The use of coarse aggregate size of more than $20 \mathrm{~mm}$ aggregate should be within $5 \%$, the maximum particle size should be less than $25 \mathrm{mmW}$. Fine aggregate is generally ordinary sand, coarse aggregate with gravel, pumice, ceram site and waste gravel, etc. constitute a permeable concrete skeleton, aggregate gradation is a serious impact on its permeability and strength factors. (3) admixture. The addition of appropriate admixtures to improve its performance, such as adding appropriate enhancers, can improve the interface strength; add appropriate water reducing agent, can improve its workability and strength; add appropriate coloring agent, so that the road more Beautiful; add suitable for lime can improve the viscosity of cement slurry, and acid rain has a neutral effect, can significantly improve its durability. (4) water generally use drinking water (80 $120 \mathrm{~kg} / \mathrm{m} 3)$.

\section{The Properties of Permeable Concrete}

Rechargeable concrete piles for the compression test reference standard, the use of universal testing machine, the specimen removed, as soon as possible to test, to avoid changes in humidity. W mold the two sides as the upper and lower pressure surface, the sample is also aligned with the press. The temperature of the sea coagulation is less than the C30 to take $0.3 \sim 0.5 \mathrm{MPa} / \mathrm{s}$ loading speed, greater than $\mathrm{C} 30$ less than $\mathrm{C} 60$ take $0.5 \sim 0.8 \mathrm{MPa} / \mathrm{s}$, when the specimen near the destruction of the beginning of the deformation of the adjustment test machine oil port to break, Break the limit. However, the pressure-bearing area of the pervious tuffy specimen is different from that of the ordinary atmosphere. The common concrete bearing area is the external dimension, and the porous part of the surface of the permeable coagulation does not bear the load, so the permeable concrete The area of the pressure area should be removed by the area of the surface area and the apparent density.

The strength of the recycled aggregate is lower than that of the natural aggregate, because the waste coagulation ghost will produce some cracks in the process of crushing, and its surface is attached with a lot of cement slurry, bone and old and new cement pulp interface is weak. So it should be strengthened to deal with and to improve its strength. North China University of Water Conservancy and Hydropower University, Chen Aifen, Wang Jing, Hohai University Zhang Qing and their research group Pi], for the quality of recycled aggregates, the FDM-II Los Angeles separator wear test machine on the regeneration Coagulation Wang was tested in order to remove the weak particles and cement mortar attached to the surface of the cement mortar, the test also on the apparent density and bulk density to be further improved, the resulting coarse aggregate related physical and mechanical properties And natural coarse aggregate physical properties of the indicators were compared.

The crushing index of recycled coarse aggregate is closely related to the strength of the original concrete. The higher the strength of the original concrete, the lower the crushing index value and the higher the crushing index than the natural coarse aggregate. Because the surface of the recycled coarse aggregate is wrapped with weak cement mortar and damage to the original foam during the crushing process, these will result in a higher crushing index of the recycled coarse aggregate.

A large number of studies have shown that, in the case of the same intensity level, due to the coarse aggregate is harder, more edges and corners, the surface rough wear, so the puffing on the pavement wear slower. The ordinary concrete surface is a weak mortar layer, wear faster, and then on the coagulation of the base layer of wear and tear. So the wear resistance of permeable 
coagulation is better than ordinary coagulation, but the water is not suitable for condensation in the cold areas.

Recycled aggregate and natural aggregate compared to the following defects: particles angular, surface rough sugar, micro-cracks (due to aggregate surface hardened cement mortar, broken reproduction caused by internal damage cracks); porosity, water absorption, Packing density is small, the crushing index is high, the strength is lower than that of natural aggregate; but the recycled aggregate permeable concrete has better wear resistance than ordinary coagulation, sound absorption noise reduction, water permeation is good, water seepage replenishes groundwater, construction waste resource utilization And other advantages is the sponge city permeable pavement material one of the best choice. It is the development direction of the future sponge paving in the future sponge city, and the physical and mechanical properties of the recycled aggregate are different from those of the natural aggregate, but the right of the recycled aggregate is different from that of the natural aggregate. The ratio of recycled aggregate is less than $50 \%$, the diameter is $10 \sim 20 \mathrm{~mm}(10 \sim 16 \mathrm{~mm}, 16 \sim 20 \mathrm{~mm}=4: 6)$, the water-cement ratio is $0.3 \sim 0.4$, the ashes is $3.5-4.5$ and the sand rate is about $10 \%$ Strength and Permeability of Permeable Concrete. In addition the recycled aggregate through the impurity (weak particles and aggregate surface cement mortar) or by adding the right amount of sand, polypropylene fiber reinforced treatment can be expected to effectively improve its strength and to ensure the permeability requirements. But the influence of the compressive strength of the solidification on the permeable coagulation, the influence of the porosity; the size of the specimen; the effect of the size of the aggregate on the surface area of the specimen; the strengthening of the permeable coagulation master; Freeze-thaw performance and other issues to be further studied.

\section{Application of Permeable Concrete in Sponge City}

First, the use of Permeable concrete in sponge city, should calculate the proportion of concrete. Only follow the scientific ratio, the preparation of concrete in order to improve the overall performance of permeable concrete structure. Before preparing the permeable concrete, it is necessary to calculate the specific proportions of the various formulated materials. Specifically, you should do the following: First, you should determine the permeability of permeable concrete, as the basis for the choice of aggregate particle size. In general, the higher the water permeability of the permeable concrete, the larger the particle size of the selected aggregate; the smaller the water permeability of the permeable concrete, the smaller the particle size of the selected aggregate. After the aggregate selection is complete, you can mix other cement materials, water and ash materials. In the calculation process the need to apply the method of volume measurement, and reasonable control of the proportion of fiber reinforcement. Second, we should evaluate the workability of permeable concrete, if the permeability of concrete is better, should be appropriate to increase the proportion of cement mortar, if the Permeable concrete workability is poor, should increase the amount of aggregate. Thirdly, after the initial batching is completed, the physical properties of the permeable concrete should be tested. When the permeability of the permeable concrete is low, more coarse aggregate should be incorporated. When the hardness of the permeable concrete is low, more cement should be incorporated. Fourth, should increase the pressure on the permeable concrete, forming a fixed shape, into the sponge city construction.

Second, the use of Permeable concrete in the sponge city, should optimize the drainage system design. Permeable concrete needs to be absorbed into the groundwater, so the need to form a highly efficient drainage system, the rainwater collection and removal. In the design of the permeable concrete structure, the location of the runoff should be reserved. Permeable concrete is very susceptible to the influence of the external environment and it should purify the surrounding environment, to avoid the water pipe cracks and other problems. In order to accelerate the penetration of rain, you can properly raise the slope of the slope. In determining the size of the permeable concrete, the amount of road water should be calculated. In general, the pavement size of Permeable concrete is one hundred and fifty to four hundred and fifty millimeters. In addition to the above work, but also need to do the following: First, the permeable surface should be controlled to 
ensure that the permeability of the permeability layer. Second, the water storage area of the permeable surface should be expanded to store water in the gap. Third, should keep the moisture flow, connecting the permeable surface layer and the soil. Fourth, should be covered in the bottom of the cloth, to ensure that the bottom of the flat.

\section{Conclusion}

Permeable concrete is with permeable, breathable, light and so on, for the sponge city pavement can effectively use the rainwater to supplement the lack of groundwater resources, and also can play a role in alleviating the role of urban heat island, Permeable concrete is the future of the ecological The Important Direction of the Development of Vegetable Green Concrete. In the construction of sponge city in the application of green ecological coagulation king, the paper to the abandoned building bubble coagulation \pm aggregate and waste tires used to permeate and can achieve garbage resources, to achieve both environmentally friendly and improve the permeability of concrete Physical for the performance and durability of the role.

\section{References}

[1] Wang Zhenshuang, Wang Baomin. Effect of rubber particles on the durability of recycled concrete [J]. Journal of Harbin Institute of Technology, 2015 (06)

[2] Xu Xinbing, Li Shengbin. Study on Recycled Aggregate and Its Performance of Waste Concrete [J]. Green Technology. 2015 (06)

[3] Ju Maosen. Study on the concept, technology and policy of sponge city construction [J]. Water Resources Development Research 2015 (03)

[4] Yang Chunfeng, Sun Mingbo, Wang Peizhu. Experimental study on strength and water permeability of waste rubber aggregate [J]. Journal of Shenyang University, 2014 (03)

[5] Lingxue Jiang. Luo Juuo: let the green roof dress up "beautiful China" [J]. Today Branch, 2013 (23)

[6] Che Wu, Yang Zheng, Zhao Yang, Li Junqi. Analysis of Waterlogging Control and Drainage System in China [J]. China Water Supply and Drainage, 2013 (16) 